\title{
CHRONOS OU KAIRÓS? \\ Qual é o "Tempo" de Formação nos Cursos Técnicos Integrados ao Ensino Médio nos Institutos Federais de Educação Ciência e Tecnologia - IFs?
}

\author{
Sidinei Cruz Sobrinho ${ }^{1}$ \\ Tamyris Proença Bonilha Garnica²
}

\begin{abstract}
RESUMO
O estudo tem por objetivo principal verificar se há evidências significativas da influência da quantidade de carga horária total e/ou duração em anos nos índices de eficiência acadêmica, e na perspectiva do currículo integrado e da formação integral nos cursos de Ensino Médio Integrado. A pesquisa deu-se com base em 57,9\% dos 38 Institutos Federais, o que equivale a $40 \%$ do total dos cursos de Ensino Médio Integrado (EMI) ofertados nos IFs até dezembro de 2018. A pesquisa estabelece comparações com base nos índices oficiais de eficiência acadêmica nos IFs e contextualiza os limites e alcances da discussão. Apresenta-se e discute-se as problemáticas a serem respondidas para a definição da duração dos cursos de educação profissional integrados ao Ensino Médio. Os resultados da pesquisa apontam para reflexões consistentes para o aprofundamento do estudo sobre o tema na organização curricular dos cursos dessa natureza e apresentam indícios consistentes de que nos cursos com maior duração os estudantes tendem a ter maior evasão e ou reprovação.

Palavras-chave: Instituto Federal. Currículo integrado. Duração de cursos. Eficiência acadêmica.

\section{CHRONOS OR KAIRÓS? WHAT IS THE "TIME" OF EDUCATION IN THE TECHNICAL COURSES INTEGRATED WITH THE BASIC EDUCATIONS DEGREE IN FEDERAL INSTITUTES OF EDUCATION, SCIENCE AND TECHNOLOGY - IFS?}

ABSTRACT

The main objective this study is to verify if there is significant evidence of influence about the amount of total hours and / or duration in years on the academic efficiency indexes, and from the perspective of the integrated curriculum and the integral formation, in technical courses integrated with the basic educations degree (High School) in Federal Institutes of Education, Science and Technology - IFs. Researching, in $57.9 \%$ of the 38 Federal Institutes, $40 \%$ of the Integrated High School courses offered at the IFs until December 2018. Establishes comparisons based on the official academic efficiency indexes at the IFs and contextualizes the limits and scope of the discussion. Showing the main problem to be answered for the definition of the duration in these courses as well and consistent reflections for further study on the theme in the curricular organization of courses of this nature; shows consistent evidence that in longer courses students may experience more academic dropout and failure.
\end{abstract}

Keywords: Federal Institutes. Integrated curriculum. Duration courses. Academic efficiency.

Recebido em: $15 / 5 / 2020$

Aceito em: 21/6/2020

\footnotetext{
Doutorando em Educação (pesquisa em Políticas Públicas Educacionais - em andamento). Mestrado em Filosofia. Especialização em Direitos Fundamentais. Graduação em Direito. Graduação em Filosofia. Aperfeiçoamento Profissional em Direito Educacional e Direito Administrativo Aplicado à Gestão Pública. Professor de do Ensino Básico Técnico e Tecnológico no Ifsul Campus Passo Fundo. Palestrante e formador de servidores nas instituições da Rede Federal de Educação Profissional Científica e Tecnológica com ênfase em Currículo Integrado e Gestão Institucional. Atua principalmente nas áreas de Educação Profissional; Gestão Pública; Direito Administrativo e Filosofia. http://lattes.cnpq.br/1511454869172404. https://orcid.org/0000-0002-8826-5745. sidineicsobrinho@gmail.com

2 Doutorado e Mestrado em Educação e Graduação em Pedagogia (Universidade Estadual de Campinas). Atuou no Ensino Superior como pesquisadora, professora e assessora pedagógica. Na Educação Básica, exerceu função de docente, diretora de ensino e consultora pedagógica. Desenvolve pesquisas relacionadas à educação, docência e formação de professores, com ênfase em Psicologia Social. Professora do Ensino Básico Técnico e Tecnológico, área de Educação, no Instituto Federal de São Paulo - Campus Avaré. http://lattes. cnpq.br/9257946096715734.https://orcid.org/0000-0003-2993-1776. tamyrisbonilha@gmail.com
} 
A análise do "estado da arte" das pesquisas sobre os IFs no Brasil (FRIGOTTO, 2018) revela milhares produções científicas e outras discussões formais sobre a formação integral e o currículo integrado nos Institutos Federais [IFs]. Este amplo estudo, no entanto, associado às evidências de outras pesquisas, dados quantitativos e principalmente às experiências concretas de tentativa de introdução de um currículo integrado nos IFs, têm demonstrado que, apesar de muitos avanços, ainda há muito que se esforçar para que a perspectiva do currículo integrado possibilite a "travessia" (FRIGOTTO; CIAVATA; RAMOS, 2005) de uma formação tecnicista do capital humano para uma formação integral, politécnica. Nesse sentido, tem-se que os fundamentos teórico-epistemológicos que sustentaram e justificaram os IFs, que se apresentam nos diversos documentos legais e institucionais, e que motivam inúmeras pesquisas e produções igualmente teóricas, não se concretizam na maioria das metodologias das organizações curriculares (duração dos cursos; cargas horárias; metodologias de avaliação; organização da matriz curricular em "grades" disciplinares que separam explicitamente na forma e no conteúdo a formação, etc.).

Em síntese, "os currículos, em várias experiências no país, [...], não estão integrados" (FRIGOTTO, 2018, p. 107). Um dos principais motivos que impedem que a travessia se faça com maior êxito não é a falta de compreensão e defesa da perspectiva da formação integral, mas a incoerência entre o discurso e a prática. Esta é explícita quando analisados os documentos e estudos formais sobre o assunto e se verifica a urgência de diminuir a distância entre o que se diz e o que se faz, buscando, justamente na lógica da integração curricular, fazer com que o discurso se torne a própria prática (FREIRE, 2005). Nesse aspecto, dada a limitação do espaço e o escopo principal deste estudo, nos deteremos sobre o que entendemos ser um dos indicadores dessa incoerência institucional para a organização do currículo integrado: o tempo de duração em anos e em carga horária dos cursos técnicos integrados ao Ensino Médio [EMI] nos IFs.

Tomaremos por compreensão de "formação integral" aquela já amplamente estudada e defendida pelos principais teóricos da área no Brasil e em relação aos IFs no que respeita a este tema: Frigotto, Machado, Ramos, Ciavata, Kuenzer et al., ao encontro da formação omnilateral e politécnica (Marx, Gramsci), tendo o "trabalho" por princípio educativo, a pesquisa por princípio pedagógico e a interdisciplinaridade como método. Ou, precisamente em termos de política educacional brasileira, a concepção de formação integral expressa na Constituição Federal de 1988 [CF/88, artigo 205] que visa ao "pleno desenvolvimento da pessoa humana, preparar para o exercício da cidadania e a qualificação para o trabalho." Sendo assim, partiremos do pressuposto destes entendimentos conceituais sem aprofundarmos aqui essa conceituação. Reiteramos o entendimento de que, embora a formação integral não se resuma a um "projeto didático ou a um tipo específico de desenho curricular, estas dimensões são verdadeiras e necessariamente devem ser objeto da preocupação e do labor dos estudiosos e educadores que se assumem comprometidos com a emancipação social" (FRIGOTTO; ARAUJO apud FRIGOTTO, 2018. p. 257)." Feitas essas considerações, passemos ao objeto, objetivo e método específicos da investigação em epígrafe. 
O objeto específico da pesquisa é a carga horária total e a quantidade de anos de duração dos cursos de EMI desenvolvidos nos IFs em âmbito nacional. Tem-se, por objetivo principal, verificar se há influência significativa da duração em relação aos índices de "eficiência" acadêmica destes cursos. A metodologia adotada é de natureza aplicada, com abordagem quantiqualitativa, cujos objetivos são exploratórios e explicativos, utilizando-se dos procedimentos de levantamento de dados, estudos documentais e análise de casos (ANDRADE, 2002; MINAYO, 2007). Foram analisados dados referentes a $40 \%$ dos cursos de EMI ofertados no país, estes distribuídos equitativamente entre $57,9 \%$ dos 38 IFs, conforme dados da Plataforma Nilo Peçanha [PNP] (2019, ano-base 2018, planilha 1.2). Os IFs foram selecionados, equitativa e proporcionalmente, pela quantidade de cursos de EMI ofertados (excluídos os cursos na modalidade de EJA), disseminados entre as cinco regiões do Brasil, conforme distribuição do IBGE (2019). Tem-se, portanto, uma amostra sólida e consistente para subsidiar as comparações realizadas e inferências a partir das informações obtidas. Para avaliação dos índices de eficiência acadêmica filtramos e utilizamos os dados apresentados pela PNP (2019, ano-base 2018, planilha 5.4), que, por sua vez, é o ambiente de coleta, validação e disseminação das estatísticas oficiais da Rede Federal de Educação Profissional, Científica e Tecnológica [RFEPCT]. No estudo, demonstramos o indicativo do cenário em âmbito nacional, bem como para teste e comprovação deste tomamos amostras específicas por cursos de maior oferta e região, a fim de descartar variáveis que podem influenciar na constituição da média nacional, tais como Índice de Desenvolvimento Humano, Desenvolvimento Econômico, diferenças culturais de acesso, permanência e êxito, entre outras.

Respaldamos o processo investigativo também no método de observação, dada a experiência dos autores no acompanhamento de inúmeras reformas curriculares em centenas de cursos oferecidos nos IFs com vistas à integração curricular. O processo dialógico constitutivo desses processos de elaboração e revisão dos PPCs carrega discursos, significados e sentidos nem sempre explicitados nos documentos institucionais formais, mas que são de grande valia para compreensão dos resultados, considerando que, se não os justificam, ao menos os explicam.

Organizamos o estudo partindo da problematização sobre a duração dos cursos de EMI nos IFs. Pretendemos apresentar os motivos que justificam especial atenção a essa discussão, principalmente em razão das tensões e contradições que a temática carrega. Em seguida apresentamos o embasamento legal, referencial para definição da duração dos cursos de EMI nos IFs e começamos a comparar o entendimento nacionalmente como "mínimo suficiente" para a titulação pretendida nesse nível, etapa, forma e modalidade de ensino com os quantitativos efetivamente praticados pelos IFs. Com base nesses dois momentos, buscamos trazer alguns elementos de fundamentação teórica que discutem com maior profundidade e propriedade os benefícios, prejuízos e riscos envolvidos num processo formativo de maior ou menor duração desses cursos, seja em carga horária e ou em anos. A partir de então, evidenciamos indicativos quantitativos que possam confirmar ou refutar as hipóteses levantadas e/ou sugerir novas hipóteses. Por fim, concluímos apresentando objetivamente os caminhos que essa discussão abre para facilitar e possibilitar a travessia pretendida da formação tecnicista para a formação integral. 


\section{POR QUE O TEMPO DE DURAÇÃO DOS CURSOS DE EMI É UM PROBLEMA?}

Uma premissa é inquestionável: há um lapso temporal a ser delimitado para duração dos cursos de Ensino Médio Integrado, tanto a duração em total de horas quanto a distribuição dessas horas em anos letivos. Isso porque se trata apenas de mais uma etapa de um nível de ensino, o que, portanto, pressupõe a existência de outras etapas e níveis de ensino. Logo, seja breve ou longa, a duração dos cursos desse nível (Educação Básica - LDB, Artigo 21 e Artigo 36 - A), etapa (Ensino Médio - LDB, artigo 35), forma (integrada - LDB, Artigo $36-C$ ) e modalidade (presencial) precisa ser definida. Isso implicará diretamente três elementos constitutivos da organização curricular no PPC: 1) carga horária total do curso (a partir de uma carga horária mínima legal, posta nacionalmente); 2) distribuição dessa carga horária em anos; 3) definição dos turnos de oferta (definidos no âmbito da autonomia da respectiva instituição de ensino).

Inicialmente cabe destacar que, nos IFs, essa discussão gira em torno de dois problemas principais: 1) Qual seria o limite máximo razoável da carga horária total de cada curso de EMI, sem que esta implique prejuízo à permanência e ao êxito dos estudantes?; 2) Distribuir essa carga horária, em três ou em quatro anos, também pode ser elemento organizador que interfere positiva ou negativamente na permanência e no êxito dos estudantes? Tais questões têm sido motivo de muita discussão e divergência no âmbito dos IFs.

Tradicionalmente, a maioria dos cursos técnicos, anteriores à promulgação do Decreto 5.154/2004 (BRASIL, 2004) e, principalmente anteriores à Lei 11.741/2008 desenvolvidos pelas instituições (Cefets, escolas agrícolas...) que compunham a rede federal de educação profissional até então e passaram a se tornar IFs com a Lei 11.892/2008, desenvolviam os cursos técnicos na forma da chamada "concomitância interna", ou seja, os alunos cursavam, na mesma instituição, o Ensino Médio paralelamente ao Ensino Técnico, geralmente em turnos inversos. Grande parte dessas unidades dispunha de moradia estudantil e refeitórios, os cursos eram ofertados, em regra, ao longo de quatro anos e, na maioria das vezes, com aulas todas as manhãs e todas as tardes, de segunda a sexta-feira, exceto durante, ao menos, o último semestre do quarto ano, o qual era dedicado basicamente à realização do estágio profissional. Ocorre que, com a introdução da possibilidade da forma articulada integrada ao Ensino Médio (LDB, Artigo 36 - A et seq.), com matrícula única, o que direciona para a concepção de educação profissional com vistas à formação integral, a maioria destas instituições, literalmente, "juntou" o curso de Ensino Médio regular com o curso técnico, sobrepondo as organizações curriculares e, embora tenha se modificado formalmente, materialmente continuaram a fazer exatamente o que faziam. A maioria das centenas de novas unidades que surgiram com a expansão dos IFs, inicialmente geridas por servidores oriundos dos modelos antigos, passaram a reproduzir tais modelos. Inúmeras pesquisas sobre a história da educação profissional no Brasil, bem como o estudo das organizações curriculares daquela época, já demonstraram isso claramente (COSTA, 2012; FRIGOTO; ARAÚJO, 2018, e outros). 
Quatro motivos posteriores à Lei $11.892 / 2008$ foram os principais motores para que a discussão sobre a duração dos cursos técnicos integrados ao Ensino Médio nos IFs, viesse à tona: 1) A Res. CNE/CEB n 6, de 20 de setembro de 2012, a qual, no Artigo 27, tem-se que a "Educação Profissional Técnica de Nível Médio, na forma articulada com o Ensino Médio, integrada [...] tem as cargas horárias totais de, no mínimo, 3.000, 3.100 ou 3.200 horas [...] " (BRASIL, 2012); 2) O Relatório do Tribunal de Contas da União (TCU, 2012), que questionou o alto índice de evasão nos cursos da RFEPCT; 3) Propostas governamentais de políticas públicas educacionais que passaram a ser chamadas de Reforma do Ensino Médio, incluindo a atual Base Nacional Comum Curricular e a organização dos currículos por habilidades e competências na direção das teorias do capital humano que contrariam as teorias e concepções de Formação Integral e de Mundo do Trabalho, ao invés de mera formação para o mercado de trabalho, como pretendiam os documentos-base e estudos norteadores da constituição dos IFs; 4) As "Diretrizes Indutoras para a oferta de cursos técnicos integrados ao Ensino Médio na RFEPCT, que foi construído pelo Fórum de Dirigentes de Ensino (FDE) do Conselho Nacional de Reitores das Instituições da Rede Federal de Educação Profissional, Científica e Tecnológica (Conif), a partir de contribuições de todo o Brasil" (CONIF, 2018). Estas Diretrizes Indutoras problematizam a discussão porque afirmam, corretamente, que

[...] para dar conta da oferta prioritária para os cursos técnicos integrados dentro do princípio da formação humana integral, é necessário discutir a diversidade de organização dos cursos no que se refere à carga horária e tempo de duração. 0 excessivo número de horas em sala de aula compromete a possibilidade de tempo/ espaço para o envolvimento do estudante em projetos de ensino, pesquisa e extensão e em ações dos núcleos inclusivos. [...] a preocupação com a permanência e o êxito, como elemento fundante da educação inclusiva, impõe uma reflexão sobre o tempo de duração dos cursos (CONIF, 2018, p. 14-15).

Com base nisso, o documento irá propor que, na organização curricular, entre outros, os IFs, em relação à duração dos cursos em anos, busquem organizá-los com duração de três anos e em relação à carga horária total dos cursos de EMI, procurem:"18. Adotar como referência de carga horária dos cursos técnicos integrados as estabelecidas na Res. CNE/CEB no. 06/2012 [...] com um máximo de 5\% sobre a carga horária total" (CONIF, 2018. p. 17). Tais Diretrizes deveriam ter sido "aprovadas no Conselho Superior, até dezembro de 2019" (CONIF, 2018. p. 15), no âmbito de cada IF. Muitos IFs aprovaram as diretrizes nos respectivos Conselhos e estão em processo de revisão dos PPCs dos cursos de EMI. Alguns outros já estavam adequados à proposta porque já haviam atendido à Res. CNE/CEB 06/2012 desde a sua publicação. Entre estes, destaque-se o Instituto Federal Farroupilha [Iffar] que, desde 2013/2014, revisou todos os projetos pedagógicos de Ensino Técnico e Superior nessa direção (SOBRINHO, 2017). Poucos IFs ainda resistem à proposição e mantêm a maioria dos cursos com duração de quatro anos e ou com cargas horárias muito superiores às máximas propostas nas diretrizes indutoras.

É imperioso frisar que, como a própria titulação do citado documento afirma, a duração dos cursos é elemento "indutor", ou seja, provoca a reflexão de outros elementos que pretendem induzir à integração curricular, ao aumento e melhoria da perma- 
nência e êxito dos estudantes e à travessia para a formação integral. Assim sendo, não é e não pode ser tomada por si só como causa suficiente para a "eficiência" pretendida. É nessa contradição eminente de se tomar elementos isolados da organização curricular como suficientes para mover a travessia que passamos a levantar as problematizações que derivam daqueles problemas principais que expusemos inicialmente.

\section{OS PROBLEMAS QUE COMPÕEM O PROBLEMA}

É comum e, diríamos, necessário, que na discussão da organização curricular um problema educacional provoque vários outros, principalmente dada a abertura dialética e a complexidade de se trabalhar temas relacionados à educação. Nesse diapasão, corroboramos a perspectiva hermenêutica gadameriana, segundo a qual "A arte de perguntar é a arte de seguir perguntando e isso significa que é a arte de pensar". "Quem quer pensar deve perguntar-se" (GADAMER, 1999a, p. 372, 381 apud DALBOSCO, 2014, p. 255, 270). Nesse sentido pretendemos levantar questões pertinentes que nos façam refletir melhor sobre a constituição da duração dos cursos de EMI, para tomadas de decisão no mínimo mais prudentes e menos contraditórias. Afinal, a principal questão escondida nessa discussão não é se os cursos devem ou não durar três ou quatro anos, terem mil ou mais horas superiores às cargas horárias mínimas previstas nacionalmente como suficientes para a formação pretendida. A principal discussão é: Quais são os critérios adotados para se chegar à conclusão de que aquela duração é a mais razoável para aquele curso e sobre qual concepção de educação tais critérios se sustentam? Leva-se em conta o perfil do egresso pretendido ou o perfil de alguns professores que ainda entendem o currículo como espaço de poder individual e não coletivo e que, portanto, tentam moldar o currículo de modo que quanto maior a carga horária das "suas" disciplinas, maior é o seu "poder" perante os demais saberes que compõem o currículo? Passemos, então, a lançar um olhar sobre essa complexidade e buscar indícios de (des)articulação que (des)favorecem a travessia.

Em reunião nacional realizada pelo Fórum dos Dirigentes de Ensino da RFEPCT (FDE/Conif), realizada no primeiro semestre de 2015, os pró-reitores de Ensino trabaIharam no levantamento de dados e discussão em rede sobre o assunto. De acordo com o FDE/Conif, o objetivo era produzir um documento propositivo para a Rede (maio de 2015, in arquivos do FDE). Este foi elaborado entre 2015 e 2018, até culminar nas Diretrizes Indutoras para a oferta de cursos técnicos integrados ao Ensino Médio na RFEPCT (CONIF, 2018). Até agosto de 2015, dos 38 IFs, 50\% produziram as informações envolvendo 236 campi, dos quais 185 ofertavam cursos de EMI. Destes 185 campi, 60,5\% já ofertavam os cursos com duração de 3 anos e 39,5\% ofertavam os cursos de EMI em 4 anos. Uma das questões feitas no questionário de levantamento dos entendimentos institucionais buscava saber qual era a proposta de cada IF para a duração dos cursos de EMI em 3, 4 anos ou outra. Sobre isso, das instituições que se manifestaram, 78,94\% foram favoráveis ao entendimento de que todos os cursos de EMI deveriam ter duração de 3 anos. Apenas um IF, representando 5,26\%, se manifestou favorável à duração dos cursos em 4 anos. Um IF ficou indefinido e um defendeu que a escolha deveria se dar conforme o entendimento de cada campi. Essa discussão se perpetuou, inclusive voltando a ser debatida em dois grandes Seminários Nacionais promovidos pelo FDE/Conif 
sobre o EMI, até culminar com as Diretrizes Indutoras para o EMI (CONIF, 2018), que manteve o entendimento nacional de se realizar os cursos de EMI em 3 anos, observado o limite de até $5 \%$ acima da carga horária mínima estabelecida legalmente. Alguns poucos IFs, porém, que discordaram dessa diretriz, não aderiram ao entendimento em Rede. Curioso esse fato, porque todos os reitores estudaram e aprovaram tais Diretrizes Indutoras no âmbito do Conif, assim como todos os reitores e pró-reitores e dirigentes de ensino, supostamente teriam debatido esses dados em suas instituições desde 2015; além disso, considere-se os Seminários Nacionais do EMI (2017 e 2018), nos quais a temática também foi apresentada e discutida para e com, literalmente, milhares de outros representantes dos IFs (reitores; pró-reitores; diretores gerais; diretores de ensino; coordenadores de cursos, entre outros). Haveria indício de precariedade na comunicação ou falta de transparência em algumas gestões entre o que se discute nos órgão de representação e o que (não) se discute nas bases? Por ora, deixamos essa temática para outro estudo específico. Identidade; coerência institucional e entendimentos coletivos também são características a serem mais bem desenvolvidas nos IFs.

Nesse sentido, dever-se-ia concluir que, apesar das divergências e da impossibilidade do consenso absoluto, o entendimento nacional, em RFEPCT, havia sido construído sólida e democraticamente após ampla consulta às bases e unidades acadêmicas. Entendemos que "Os antagonismos não desaparecerão... não haverá consenso... mas este não é o problema. [...] É preciso explicitar posições para que se possa constituir decisões e novas posições, em um continuum de processos hegemônicos" (LACLAU; MOUFFE, 2015 apud ABDIAN, 2018, p. 118). Por isso, também defendemos que "o consenso a ser construído é a luta prioritária pelo ensino médio universal, na perspectiva da escola unitária, omnilateral, tecnológica ou politécnica como direito social e subjetivo" (FRIGOTTO, 2018, p. 57).

Um dos problemas que compõem este problema é: embora não se esteja defendendo uma padronização autoritária e impositiva de currículo, se é para que cada IF (também respeitados os limites e alcances das especificidades locais e regionais e da autonomia institucional de cada autarquia) faça o que "bem ou mal" entende, qual é a razão de se manter o Conif e fóruns como o de ensino, pesquisa, extensão, administração, e outros, que se reúnem frequentemente em âmbito nacional sob o discurso, justamente, de discutir a RFEPCT? Este contexto de tensões e contradições baseadas em interesses individuais e corporativistas já esteve presente desde o início do processo de constituição dos IFs. ${ }^{3}$

Em regra, nestas discussões, levando em conta o que indicam as evidências, os posicionamentos sobre a duração dos cursos são mais baseados em meras opiniões ou em experiências isoladas em alguns cursos e casos específicos. Buscamos catalogar os dados disponíveis a fim de sabermos, por exemplo, se após uma década da institucionalização dos IFs e da larga expansão de unidades/campi, qual é hoje a duração dos cursos de EMI nos IFs em anos? Como estão distribuídas as cargas horárias totais desses

Recomendamos a leitura da tese doutoral: FIGUEIREDO, Amilton de Moura. IFs. Contexto da influência, produção do texto e tensões, na construção da política pública, criação dos IFs. 2019. Tese (Doutorado) - IFRS, Unisinos, São Leopoldo, 2019. 
cursos em âmbito nacional, quando analisamos cursos de EMI da mesma habilitação específica? Qual é a medida das diferenças dessas cargas horárias? Por quais motivos, no âmbito do mesmo IF, sob (teoricamente) a mesma concepção de educação profissional, as mesmas regras de organização didática; as mesmas legislações educacionais; com os mesmos objetivos e finalidades, missão, visão e valores, previstos nos Planos de Desenvolvimento Institucional [PDI]; na mesma região geográfica, com cultura, desenvolvimento econômico e social muito semelhantes; às vezes na mesma cidade ou microrregião; no mesmo nível, etapa, forma e modalidade de ensino; cuja formação afere o mesmo certificado, com a mesma habilitação técnica integrada ao Ensino Médio; na maioria das vezes apenas ofertado em campi diferente, mas que pertencem à mesma autarquia, identificamos diferenças de duração tão díspares entre uma oferta e outra? Por quais motivos, no mesmo cenário, em um campus o curso é desenvolvido com, por exemplo, carga horária total de 3.350 horas/relógio em três anos e em outro campus é desenvolvido com 3.340 horas em quatro anos? Por quais motivos alguns cursos de EMI apresentam cargas horárias totais dentro das quais seria possível o estudante realizar duas habilitações técnicas específicas ou uma habilitação técnica específica mais uma especialização técnica de nível médio (Artigo 31, Res. CNE/CEB 06/2012)? Existe confusão entre ensino integrado, turno integral e escola em tempo integral? Se a quantidade de disciplinas e horas de duração do curso é para possibilitar maior "qualidade" da formação, por quais motivos, em regra, na média nacional, nos cursos com maior duração em carga horária total, há maior índice de evasão e retenção? Como se resolve a questão da mobilidade acadêmica intercampi? Será que as concepções de currículo integrado e de formação integral foram entendidas no âmbito dos IFs? É possível afirmar pela predominância de uma regra geral, levando-se sempre em conta a exceção dos casos bem específicos nos quais realmente seguir tal regra seria mais prejudicial que benéfico? Com quais critérios e com base em que métodos e quais procedimentos estão sendo avaliados os cursos de EMI em toda sua complexidade para se gerar entendimentos mais consistentes para além do senso comum e da mera opinião dos indivíduos?

Enfim, estes e muitos outros problemas compõem o problema sobre a definição da duração dos cursos de EMI nos IFs. Obviamente não temos a pretensão, nem teríamos condições de aprofundar e sequer responder a todos estes questionamentos. Reiteramos, mais que pretender responder, o objetivo é auxiliar a pensar melhor e com fundamentos mais consistentes sobre o assunto em pauta.

\section{QUAL É A DURAÇÃO MÍNIMA ESTABELECIDA NACIONALMENTE PARA OS CURSOS DE EMI?}

À primeira vista a resposta a esta pergunta pode parecer óbvia, porém ao pesquisar os projetos pedagógicos de cursos de EMI identificamos que muitos têm seguido caminhos interpretativos falaciosos para estabelecer a composição da carga horária mínima exigida legalmente para estes cursos.

Como já mencionamos, uma das práticas inerentes à transição para a forma integrada foi a mera sobreposição dos cursos de Ensino Médio regular à habilitação profissional do Ensino Técnico. Nesse ato foram simplesmente somadas as cargas horárias de ambos os PPCs, gerando cursos, que identificamos, com mais de 4.900, e em alguns 
casos mais de 5.100 horas, motivo que levou, por consequência, para poder atender a toda essa carga horária, que se ofertasse o curso em 4 anos com aulas em tempo integral, em dois turnos diários, de segunda à sexta-feira no mínimo por 3,5 anos, ${ }^{4}$ deixando mais um semestre para atender aos estágios e trabalhos de conclusão de curso. Essa forma de composição da carga horária total dos cursos de EMI é equivocada porque contraria, não só a lógica de composição das cargas horárias mínimas legais, como também, e principalmente, os próprios conceitos de Ensino Médio Integrado, currículo integrado e formação integral.

Outro raciocínio equivocado é de natureza da interpretação da legislação educacional sobre a carga horária. Nesse caso, utiliza-se da ideia de que, para não haver prejuízo à formação geral (LDB, Artigo 36-A), dever-se-ia tomar a carga horária mínima da formação geral nessa etapa da educação básica (LDB, Artigo 24, I), distribuída em, no mínimo, 3 anos (LDB, Artigo 35), portanto, 2.400 horas, e somar à carga horária do respectivo curso conforme o previsto no Catálogo Nacional de Cursos Técnicos [CNCT], que seria, conforme o curso, $800,1.000$ ou 1.200 horas. Assim, concluíam que a carga horária mínima dos cursos de EMI teria, conforme o curso respectivo ao CNCT: 3.200, 3.400 ou 3.600 horas.

Tal situação agravou-se com o advento da Reforma do Ensino Médio (Lei. 13.415/2017) que incluiu ao Artigo 24, I, da LDB, o §1ㅇ․ Nesse caso, alguns servidores começaram a solicitar a necessidade de alterar os PPCs do EMI para se "adequar" à Reforma do Ensino Médio, sob o argumento de que era Lei, e que, em razão disso, fosse acrescentado no mínimo mais 200 horas para a formação geral. Novamente raciocínio falacioso, porque a Reforma do Ensino Médio não estabeleceu tais cargas horárias para o EMI e a interpretação jurídica feita dessa forma fere a boa hermenêutica jurídica.

O Artigo 36-B;§único I. (LDB) é claro ao afirmar que "A educação profissional técnica de nível médio será desenvolvida nas seguintes formas: I - os objetivos e definições contidos nas diretrizes curriculares nacionais estabelecidas pelo Conselho Nacional de Educação; [...]". Ou seja, abre a possibilidade para que o CNE regulamente, em norma infra à LDB, diretrizes que disponham mais detalhadamente a organização da educação técnica. E foi justamente o que fez o CNE ao promulgar a Res. CNE/CEB. № 06/2012, que define Diretrizes Curriculares Nacionais para a Educação Profissional Técnica de Nível Médio. Nestas, restará claro, no artigo 27, que:

Os cursos de Educação Profissional Técnica de Nível Médio, na forma articulada com o Ensino Médio, integrada ou concomitante em instituições de ensino distintas com projeto pedagógico unificado, têm as cargas horárias totais de, no mínimo, $3.000,3.100$ ou 3.200 horas, conforme o número de horas para as respectivas habilitações profissionais indicadas no Catálogo Nacional de Cursos Técnicos, seja de $800,1.000$ ou 1.200 horas (BRASIL/CNE/CEB, 2012).

Na pesquisa realizada identificamos apenas dois cursos com duração de 3,5 anos. 
A Res. CNE/CEB n. 06/2012, portanto, atende ao ordenamento da própria LDB, regulamentando a carga horária a fim de evitar a sobreposição. Não se trata, porém, de, a partir das referidas diretrizes, concluir que, por exemplo, num curso previsto no CNCT para ter no mínimo 1.200 horas, ao ser ofertado na forma integrada e, portanto, somadas 2.400 horas, passando a ser um curso com 3.600 horas, para seguir a Res. CNE/ CEB 06/2012, seria necessário diminuir 400 horas, prejudicando assim o ensino, mas sim de que, no mínimo 400 horas deste curso podem ser ofertadas de forma integrada e/ou eliminando sobreposições de conteúdos e práticas. Nesse sentido, as diretrizes em discussão têm o caráter também indutivo que visa a forçar o planejamento de práticas integradoras justamente para evitar o prejuízo à formação dos educandos.

Cabe destacar que a Res. CNE/CEB 06/2012 foi amplamente discutida em âmbito nacional, devidamente fundamentada e justificada por profissionais da educação altamente qualificados na área, inclusive uma equipe formada por representantes oficiais dos IFs participou diretamente da elaboração destas diretrizes, incluindo amplo debate no Conif e fóruns pertinentes, e se concluiu que 3.000, 3.100 ou 3.200 horas seria uma carga horária suficiente para oferecer, com qualidade, cursos de EMI. Por qual motivo, então, nos próprios IFs, há vários cursos de EMI que ainda apresentam uma carga horária total muito superior a estas já entendidas e consolidadas como suficientes? Incoerência? Afinal, quais critérios têm sido adotados na elaboração dos PPCs e das organizações curriculares para se definir um limite máximo a estas cargas horárias em cada curso?

Trata-se, portanto, do fato de que quando se estabelece também um teto a ser observado para carga horária total, esse limite leva a se refletir sobre todas as demais partes da organização curricular, dado que, inquestionavelmente se distribuem no espaço/tempo, não podendo se perpetuar ao infinito ou até onde vai a vontade e/ou a condição individual de se inserir quantitativos no currículo sem muitos critérios claros ou com base em critérios que contrariam a concepção de educação e de organização curricular que se diz pretender, ao menos formalmente. Feitas essas considerações, passamos para a apresentação dos dados concretos sobre a duração dos cursos de EMI nos IFs em âmbito nacional.

\section{QUAL É A DURAÇÃO DOS CURSOS DE EMI NOS IFS?}

Buscamos tabular dados concretos para traçar um cenário, em plano nacional, sobre a duração dos cursos de EMI desenvolvidos nos IFs. Considerando a fonte de dados oficiais da RFEPCT, filtramos, na Plataforma Nilo Peçanha - PNP, (2019, ano-base 2018, Planilha 1.2 - Tipo de Curso), o total de oferta de cursos presenciais de EMI nos IFs. O filtro indicou a oferta de 1.996 cursos de EMI (excluídos os na modalidade de EJA). Dos 38 IFs criados pela Lei 11.892/2008 (Artigo 5ㅇ), ordenamos a distribuição entre as cinco regiões do país, conforme organização do IBGE (2019). A partir desta organização optamos por pesquisar os cursos de EMI ofertados por 22 IFs, contemplando assim uma amostragem de $57,9 \%$ dos IFs do país, distribuídos entre as regiões. A escolha dos 22 IFs deu-se com base no quantitativos de cursos de EMI ofertados em cada um, de modo que pudéssemos analisar a duração destes em $100 \%$ dos cursos de EMI de cada IF estudado e pudéssemos manter um quantitativo proximal coerente entre as regiões e com IFs de diferentes Estados e distribuídos geograficamente dentro de cada região estudada. As- 
sim, obtivemos um total de 795 cursos de EMI, o que representa $40 \%$ dos cursos de EMI nos IFs, distribuídos equitativamente ao quantitativo de ofertas em cada região. Como a PNP não apresenta a duração dos cursos em carga horária total e em anos, acessamos os sites de cada IF selecionado a fim de coletar os dados referentes à duração em anos e carga horária total de cada curso de EMI. Com base nesses dados tabulamos os mesmos segundo a duração em carga horária total, anos e turno(s) de oferta, separados entre si pelo referencial da carga horária mínima legal (3.000, 3.100 ou 3.200 horas) e respectiva denominação de cada curso bem como o link da fonte consultada. Na sequência, cruzamos esses dados de acordo com os critérios de duração em anos; em cargas horárias totais agrupadas por lapso sequencial de 200 horas acrescidas à carga horária mínima e por porcentagem de carga horária superior à mínima; a duração dos cursos em anos e o índice de eficiência acadêmica (o que inclui a taxa de conclusão, evasão e retenção) que contabiliza o ciclo de cada curso, portanto aqueles que já concluíram o prazo de duração previsto no PPC (conforme PNP 2019, ano-base 2018, planilha 5.4). Os dados foram coletados nos sites institucionais e na PNP, entre 6 e 17 de março de 2020. Esse cruzamento nos possibilita um panorama e uma média geral em âmbito nacional. Em seguida, para levar em consideração especificidades e variáveis significativas, tais como: índice de desenvolvimento humano, renda per capita média dos estudantes; condições de acessibilidade geográfica; diferenças culturais, sociais, políticas, econômicas, eixos tecnológicos, etc., realizamos cruzamento com base nos mesmo critérios, porém entre IFs e cursos da mesma região e entre cursos da mesma denominação e habilitação específica, dado que estes implicaram um perfil mais próximo de egressos e de ingressos dos cursos. Os dados foram coletados no decorrer do mês de março de 2020. Em síntese, traremos os extratos principais dessa pesquisa, dado que o espaço aqui disponível não permite apresentar todos os gráficos e análise produzidos e que ainda podem ser feitos, porém, seguida a metodologia e métodos explicitados, o leitor interessado poderá verificar e aprofundar os estudos nessa direção.

Sobre a comparação da carga horária dos cursos de EMI ofertados nos IFs em relação à carga horária mínima legalmente prevista, temos:

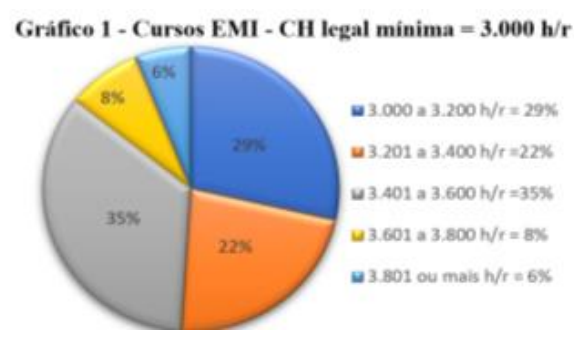

Gráfico 3 - Cursos EMI - CH legal mínima $=3.200 \mathrm{~h} / \mathrm{r}$

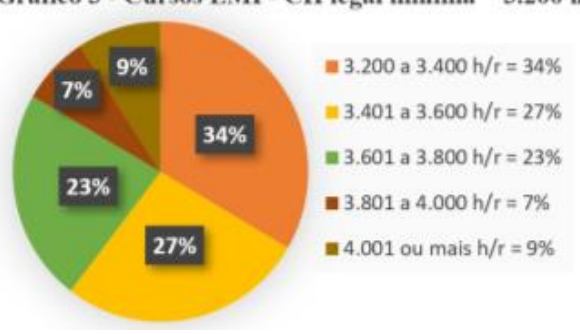

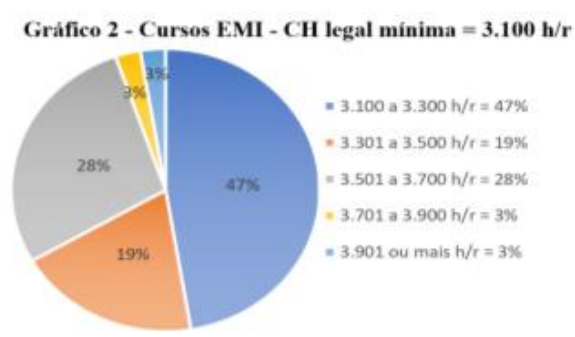

Gráfico 4 - Cursos EMI - \% de CH superior a CH legal mínima $(3.000,3,100$ ou $3.200 \mathrm{~h} / \mathrm{r})$

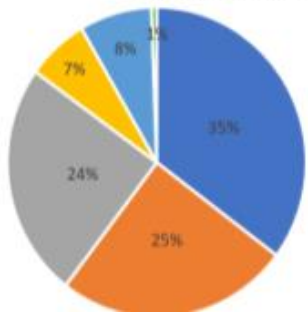

- $\mathrm{CH}$ ate $200 \mathrm{~h} / \mathrm{r}>\mathrm{CH} / \mathrm{min}=35 \%$ - $\mathrm{CH}$ entre $201 \mathrm{e} 400 \mathrm{~h} / \mathrm{r}>\mathrm{CH} / \mathrm{min}$. $=25 \%$ - $\mathrm{CH}$ entre 401 e $600 \mathrm{~h} / \mathrm{r}>\mathrm{CH} / \mathrm{min} .=24 \%$ - $\mathrm{CH}$ entre 601 e $800 \mathrm{~h} / \mathrm{r}>\mathrm{CH} / \mathrm{min},=7 \%$ - Acima de $801 \mathrm{~h} / \mathrm{r}>\mathrm{CH} / \mathrm{min}$. ou mais. = $8 \%$ - Năo identificado $=1 \%$

Fonte: Elaboração dos autores. 
Utilizamos o agrupamento de cursos por lapso sequencial de cada 200 horas acrescidas à carga horária mínima, levando em consideração o entendimento já firmado nacionalmente pelo IFs (CONIF/FDE, 2018), de organizar os cursos de EMI com até $5 \%$ acima da carga horária mínima legal. Assim, por exemplo, um curso cuja carga horária mínima legal fosse de 3.200 horas, nos IFs poderia ser organizado com até 3.360 horas. Consideramos aqui, como razoável, uma margem de $6,25 \%$, o que equivaleria a até 200 horas acima da mínima. Sequenciamos essa margem até cinco vezes, dado que muitos cursos chegam a ter até 800 horas acima da mínima, e alguns, acima disso. Limitamos à 800 horas porque esta seria a carga horária suficiente para o educando cursar outra habilitação técnica (de 800 horas, conforme o CNCT), ou Ensino Médio regular mais um curso técnico subsequente, o que tonaria inócua a proposta da formação técnica integrada ao Ensino Médio, seja pela sobrecarga de horas de formação ou pela extensão da duração em quatro anos.

Chamamos a atenção, ainda, para o lapso temporal de até 400 horas acima da carga horária mínima porque, no mesmo raciocínio, o estudante poderia cursar o EMI e realizar mais uma ou duas especializações técnicas (Res. CNE/CEB 06/2012, Artigo 31). No caso dos Gráficos 1 a 3 podemos observar que os cursos cuja carga horária mínima legal é de 3.000 horas tendem mais a ultrapassar a margem de acréscimo de 6,25\%, seguidos dos cursos de 3.200 horas, sendo que entre os cursos de 3.100 horas, $47 \%$ deles permanecem na margem de até $6,25 \%$, chegando estes, em média, a 3.300 horas de carga horária total. Quantitativo este (entre 3.200 horas e 3.400 horas) mais facilmente distribuído em 3 anos de duração sem necessidade de aulas em tempo integral, em dois turnos diários, de segunda à sexta-feira. Na média geral, 35\% dos cursos de EMI permanecem na margem de acréscimo de até $6,25 \%$ da carga horária, e $25 \%$ na margem de carga horária total até aproximadamente 13\% acima, conforme demonstra o gráfico 4 . Durante a pesquisa nos sites institucionais, observamos que esse quadro se alterou, significativamente, a partir dos anos 2015/2016, datas em que a maioria dos PPCs foram alterados, acreditamos, já em razão do acompanhamento das discussões que vinham sendo realizadas no âmbito da rede conforme o cenário que demonstramos no primeiro item deste trabalho.

No que se refere à duração dos cursos de EMI em anos, temos, em síntese, o seguinte:
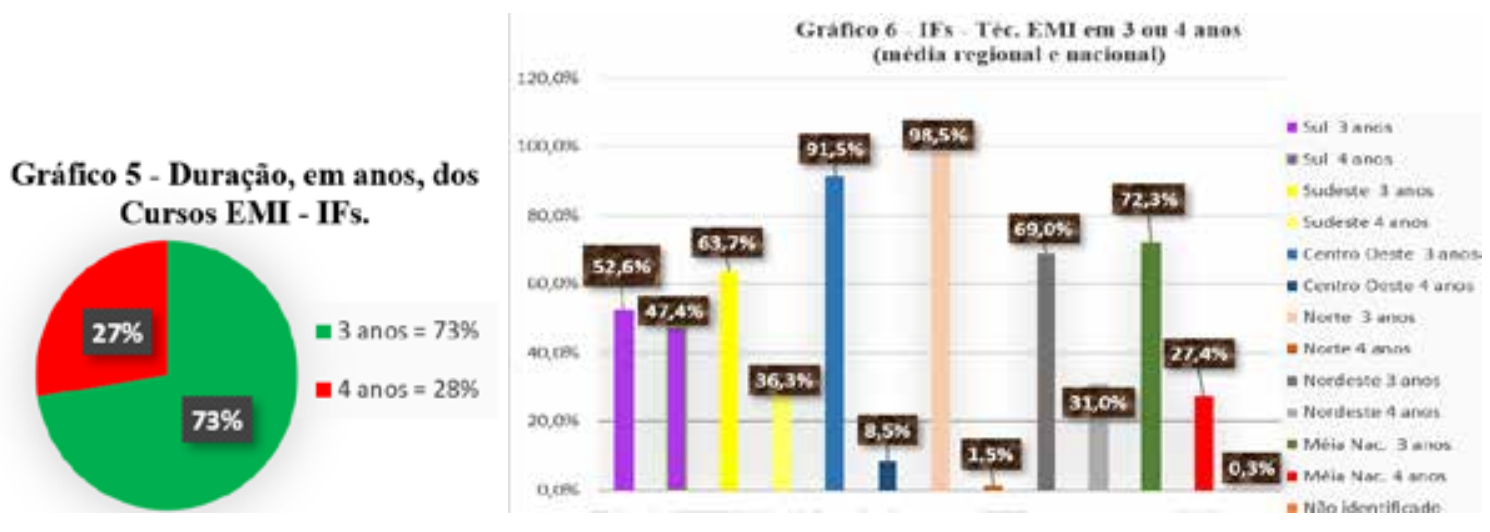

Fonte: Elaboração dos autores. 
Como revela o Gráfico 5, a maioria dos IFs já organiza os cursos de EMI com duração de 3 anos. Também nesse caso, identificamos que a maioria dos PPCs, cujos cursos tinham duração de 4 anos, reduziram para 3 anos nas reformulações realizadas a partir de 2015/2016. Alguns cursos, porém, embora tenham reduzido os cursos que antes eram ofertados em 4 anos com aulas em um turno diário, passaram a ofertar os cursos em 3 anos, mas mantiveram a carga horária total dos cursos com 400 horas ou mais acima da carga horária mínima legal, com grande número de disciplinas e tendo de distribuir essa carga horária total em dois turnos diários, de segunda à sexta-feira. Quando verificada a eficiência acadêmica desses cursos, percebe-se que eles apresentam menor índice de eficiência que aqueles cursos que também diminuíram a carga horária total e o número de disciplinas, adotando práticas mais integradoras e na perspectiva da formação integral, menos preocupados com o excesso de conteúdos e cargas horárias. No Gráfico 6 realizamos a comparação de duração dos cursos em 3 ou 4 anos por região estudada, de modo que é possível perceber quais regiões e IFs estão mais próximos do atendimento às Diretrizes Indutoras (CONIF/FDE 2018) no que tange à oferta dos cursos de EMI em 3 anos.

A título de exemplificação, filtramos os indicadores trabalhados para o curso Técnico em Agropecuária, um dos que têm maior oferta do respectivo Eixo-Tecnológico [CNCT], e comparamos o índice de eficiência acadêmica destes cursos utilizando o indicador da média nacional (nos 38 IFs), a média nos IFs pesquisados (22 IFs), a média nos cursos com duração de 3 anos e cargas horárias totais inferiores ao máximo de acréscimo de 6,25\% à carga horária mínima e a média nos cursos com duração de 4 anos e cargas horárias totais acima do acréscimo de 13\% (400 horas ou mais) à carga horária mínima.

Como se pode verificar pelo Gráfico 7, a seguir, a diferença acima de $10 \%$ é significativa. Isso porque, se considerarmos que esse padrão se mantém, e levarmos em conta que, de acordo a PNP (2019 ano-base 2018, Planilha 1.4), das 228.326 matrículas em cursos de EMI presenciais nos IFs, $20 \%$ constam como retidos ou evadidos, essa mudança da organização curricular, se reduzida a duração dos cursos para 3 anos e com cargas horárias totais não superiores à média de $6,25 \%$, resultaria no aumento de $50 \%$ no índice de eficiência acadêmica dos cursos de EMI em âmbito nacional. Obviamente, reiteramos, alterações estas sempre acompanhadas e integradas à revisão das demais dimensões da organização curricular.

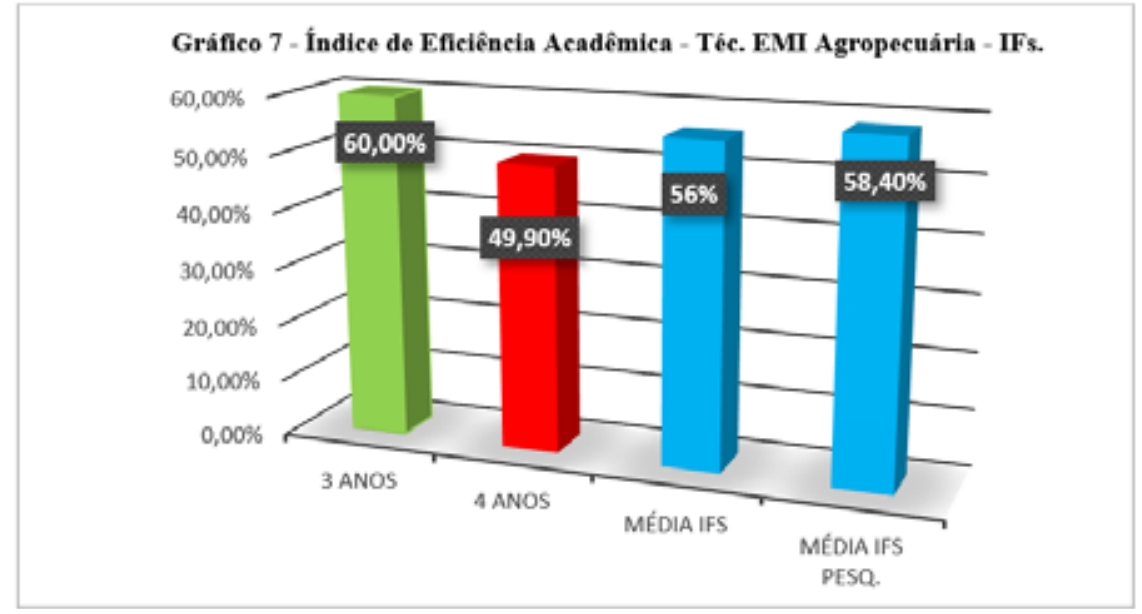

Fonte: Elaboração dos autores. 
Realizamos o mesmo filtro para cursos Técnicos em Administração e Técnicos em Informática, que são de Eixos Tecnológicos diferentes, mas que também são os que têm maior índice de oferta nos IFs, evitando assim a disparidade dos resultados pela especificidade regional e de organização de alguns IFs. Mesmo assim, chegamos às mesmas conclusões em termos de diferença no que respeita à eficiência acadêmica. Outro padrão que se repete nesses exercícios é o de que nos cursos com duração de 4 anos há maior índice de evasão que naqueles com duração de 3 anos; nos cursos com duração de 3 anos e carga horária total acima de 6,25\% da carga horária mínima legal e com aulas presenciais no matutino e no vespertino, de segunda à sexta-feira, há maior índice de reprovação; nos cursos em 4 anos com cargas horárias superiores a 6,25\% da carga horária mínima, mas com aulas apenas em um turno diário, ocorre menor índice de reprovação e maior índice de evasão, quando comparados aos de igual carga horária e em 3 anos com dois turnos de aula.

Exercício semelhante realizamos filtrando os dados na análise de $100 \%$ dos cursos de EMI nos três IFs do Estado do Rio Grande do Sul (Iffar, Ifsul e IFRS). Isso pelos seguintes motivos metodológicos: 1) menor índice de desigualdade sociocultural e econômica entre os estudantes destes cursos nos três IFs; 2 ) a maioria dos demais Estados do país tem apenas um IF, o que dificulta comparar instituições com organizações didático-pedagógicas distintas e na mesma região; 3 ) diferentemente dos demais Estados nos quais há mais de um IF, os três IFs do RGS apresentam uma distinção peculiar no tema abordado. Isso porque $100 \%$ dos cursos de EMI do Iffar são realizados em 3 anos, enquanto no Ifsul 88,4\% são realizados em 4 anos e no IFRS 30\% dos cursos são realizados em 3 anos. Embora, no entanto, assim como no Ifsul, no IFRS a maioria dos cursos seja realizada em 4 anos (70\%), ao contrário do que ocorre no Ifsul, as cargas horárias totais dos cursos em 4 anos no IFRS são, em regra, significativamente menores que as realizadas nos cursos em 4 anos no Ifsul. Além disso, o IFRS encontra-se, desde 2017/2018, passando por muitas alterações na organização didático-pedagógica institucional e com base nas discussões nacionais sobre o currículo integrado e na direção das orientações dadas pelas Diretrizes Indutoras (CONIF/FDE, 2018), enquanto que no Ifsul, até momento desta pesquisa (março de 2020) a proposta orientada pelo Conif para aprovação em todos os IFs ainda em 2019, não foram aprovadas e sequer apresentadas e discutidas nos campi. Além disso, o Iffar foi o primeiro IF do Brasil a construir nos anos de 2013 e 2014/I uma proposta em nível institucional, reformulando $100 \%$ dos cursos numa perspectiva mais em direção à da integração curricular, inclusive para cursos técnicos subsequentes e em nível superior, portanto já foram realizados dois ciclos completos em que os todos os cursos de EMI do Iffar, no que respeita à duração, são realizados em 3 anos e com cargas horárias totais não superiores a $5 \%$ da carga horária mínima legal.

Temos, assim, um cenário bastante emblemático de estudo comparativo entre cursos de maior e menor duração, entre instituições com organizações didático-pedagógicas consideravelmente diferentes, porém com poucas variáveis externas significativas, principalmente no que se relaciona às de desenvolvimento humano e desenvolvimento econômico dos públicos envolvidos. Nesse caso, os resultados reforçaram o que já vinha 
sido identificado anteriormente quando analisados em âmbito nacional. Veja-se que o índice de eficiência acadêmica do Iffar é $8,9 \%$ maior que no IfSul, próximo ao quadro comparativo em nível nacional, de 10\%:

\section{Gráfico 8 - Índice de Eficiência Acadêmcia- Téc. EMI em 3 ou 4 anos} IFFAR x IFSUL $x$ IFRS.

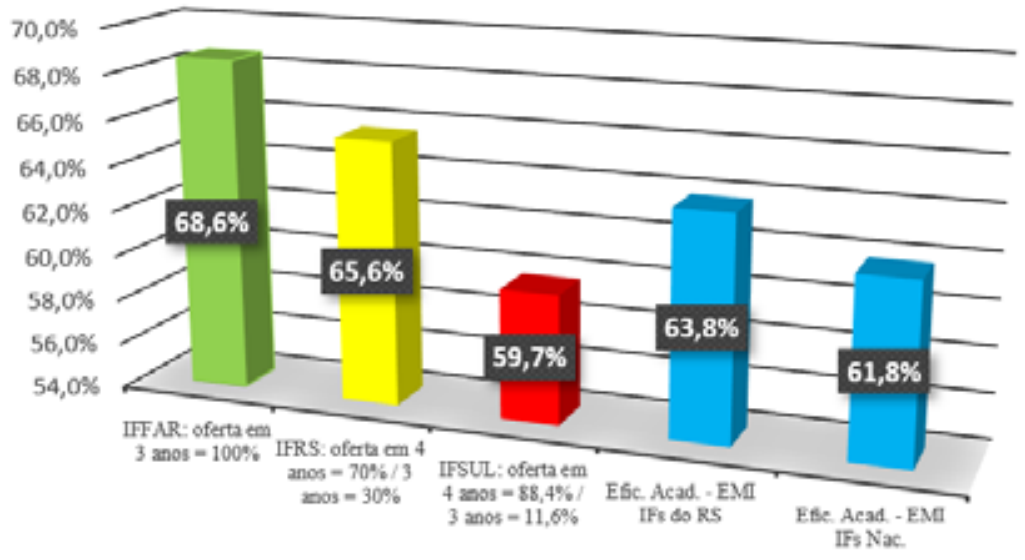

Fonte: Elaboração dos autores.

Em síntese, reiteramos, a complexidade que envolve a formação integral e o currículo integrado vai muito além do tempo de duração dos cursos de EMI, porém é inquestionável que essa discussão é uma definição importante a se considerar e discutir com maior seriedade os critérios do que simplesmente afirmar, sem dados e embasamento teórico fortes, que essa ou aquela duração é melhor ou pior. Como demonstramos, entretanto, entre inúmeras outras comparações possíveis que tendem a levar para o mesmo resultado, os cursos com duração da carga horária total com, em média, no máximo entre $5 \%$ e $10 \%$ superior à carga horária mínima prevista legalmente pela Res. CNE/CEB 06/2012 e com duração de 3 anos, apresentam, em âmbito nacional, maior eficiência acadêmica, com menores índices de evasão e retenção e, portanto, maior permanência e êxito nos cursos de EMI ofertados nos IFs, salvas as devidas especificidades e exceções à regra.

Com base nesses dois momentos discutidos até aqui, apresentaremos alguns elementos de fundamentação teórica que discutem com maior profundidade e propriedade os benefícios, prejuízos e riscos envolvidos num processo formativo de maior ou menor duração desses cursos, seja em carga horária e/ou em anos.

\section{A EDUCAÇÃO INTEGRAL E OS “TEMPOS” DE INTEGRAÇÃO}

"Educação integral, em última instância, é um pleonasmo: ou a educação é integral, ou não é educação" (PARO, 2009, p. 14). Consoante às ideias já defendidas no presente artigo, cabe destacar que embora com significados diferentes, "educação integral" e "educação em tempo integral" têm sido, historicamente, compreendidas como faces da mesma moeda, ao menos no contexto das políticas públicas educacionais levadas a cabo na metade do século 20, as quais, alicerçadas na ampliação sistemática da jornada escolar, contribuíram para a difusão do entendimento de que mais tempo na escola é sinônimo de mais aprendizagem, ou uma aprendizagem qualitativamente melhor. 
Não obstante a educação integral e em tempo integral tenham registro no Brasil desde a década de 50 do século 20, com a criação do Centro Educacional Carneiro Ribeiro, idealizado por Anísio Teixeira e, posteriormente, na década de 80, com a fundação do Centro Integrado de Educação Pública, por Darcy Ribeiro, os estudos nacionais sobre a temática foram promovidos, principalmente, a partir da década de 80 , com o crescente debate acerca da relação quantidade e qualidade da educação, cujos efeitos propiciaram condições para a incorporação da educação integral à agenda das políticas públicas. Nesse sentido, destaca-se a promulgação da Constituição Federal de 1988, que consubstanciou a educação como um direito social fundamental, e da edição de normas regulamentadoras para garantia de tal direito, entre elas: o Estatuto da Criança e do Adolescente - ECA/1990, a Lei de Diretrizes e Bases da Educação Nacional - LDB/1996 e o Plano Nacional de Educação - PNE, as duas últimas normas que estabeleceram a ampliação progressiva da jornada escolar como orientação para a política pública educacional com a finalidade de dirimir desigualdades sociais e fomentar, de forma democrática, as oportunidades de aprendizagem.

$\mathrm{Na}$ literatura sobre o tema identificam-se diferentes concepções a respeito da relação quantidade versus qualidade ou, em outras palavras, a relação causal entre a ampliação da carga horária curricular e o rendimento escolar. No cenário internacional, estudos sobre a relação entre jornada escolar e desempenho educacional dos estudantes (EIDE; SHOWALTER, 1998; LEE; BARRO, 2001; WOESSMAN, 2003; PISCHKE, 2007) não são consensuais quanto aos efeitos positivos de tal medida para a melhoria da aprendizagem, de modo que alguns identificam influência positiva da ampliação da jornada escolar; outros apontam que há pouca significância desse fator para a aprendizagem, e em alguns casos houve até mesmo um efeito paradoxal, isto é, a ampliação do tempo na escola implicou piora no desempenho dos alunos, tendo em vista a produção de relações afetivas negativas e desgastadas entre os alunos, o conhecimento e a escola, constatações essas que vão ao encontro do que identificamos nos dados anteriormente expostos.

De modo geral, os estudos apresentam variações conforme a área do conhecimento analisada e fatores socioeconômicos, o que corrobora o entendimento de que os processos de aprendizagem são atravessados por múltiplas questões e condicionantes, mostrando-se inapropriada uma leitura aligeirada dos resultados/índices de rendimento escolar à luz de fatores isolados, tais como: tempo de permanência do aluno na instituição escolar, carga horária total ou duração do curso, em anos. Há consenso de que a mera ampliação do tempo de permanência ou da carga horária dos cursos não garante mais aprendizagem, ou uma aprendizagem de "mais qualidade". Por exemplo, os estudos de Cavaliere (2002) sobre a experiência de educação em tempo integral no Rio de Janeiro evidenciam que a ampliação da jornada teve efeitos maléficos sobre o desempenho escolar dos alunos. Franco (2008) afirma que alunos que estudam mais de cinco horas na rede privada têm melhores notas que os alunos da rede pública nas mesmas condições ou com jornada maior. Mais uma evidência de que o número de horas que o aluno permanece na escola não é fator, isoladamente, determinante para a melhoria da aprendizagem. 
Nesse contexto, Cavaliere (2002) chama a atenção para a importância de romper paradigmas quanto ao tempo escolar, argumentando que o tempo de permanência dos alunos na instituição escolar não deve ser deliberadamente ampliado ou reduzido, mas qualitativamente transformado. Um tempo de escola organizado de forma convencional e meramente duplicado em horas é desnecessário e ineficaz. A proposta de ampliação do tempo diário de escola só faz sentido, [...] se trouxer uma reorganização inteligente desse tempo [...] (CAVALIERE, 2002, p. 13).

Essa sucinta explanação da literatura sobre o tema leva-nos a inferir o quanto a questão precisa ser mais bem debatida e analisada no meio acadêmico, sobretudo a partir de dados educacionais que contemplem as instituições federais que adotam o sistema de jornada integral, com os currículos de formação geral integrados à formação profissional, cuja função social deveria concorrer para a formação integral, e não apenas em tempo integral.

A partir de resultados de inúmeros estudos que analisam a realidade específica dos Institutos Federais, além das nossas experiências de atuação neste contexto, constatamos, frequentemente, discursos e práticas assentados na crença da relação causal entre a ampliação da carga horária e a melhoria dos processos de aprendizagem. Nessa lógica, a representação social que se constrói em torno do que se classifica como uma "educação de qualidade", que concorreria para uma melhor preparação do egresso, remete à concepção conteudista de educação, em que há primazia do conteúdo sobre o processo (meio e condições em que se desenvolve a relação ensino e aprendizagem), logo, tende a contemplar um grande rol de conteúdos que, por sua vez, demandam mais tempo (horas-atividade) para serem aprofundados, ampliados e/ou, simplesmente, abordados. A ênfase nos conteúdos que para além do contexto escolar tendem ao infinito, tira o foco dos procedimentos e dos meios nos quais se desenrola a aprendizagem e reduz a perspectiva de formação mais ampla do sujeito, considerando seus múltiplos aspectos afetivo, cognitivo, físico, social e outros conjuntamente.

Diante disso, há que mobilizarmos esforços para que as instituições escolares construam caminhos que levem à educação almejada. É preciso empreender energia, conhecimento e recursos para consolidação da concepção de educação integral entre todos aqueles que fazem parte do cotidiano escolar, em especial os docentes que se apegam a paradigmas obsoletos para justificar práticas conservadoras e de natureza tradicionalista.

Para as instituições, a exemplo dos Institutos Federais, que defendem, ainda que no discurso ou na forma da lei, a concepção de educação integral e que têm por finalidade a formação omnilateral dos sujeitos na perspectiva de emancipação e transformação social, na contramão da lógica do capital humano, torna-se imperativo o rompimento com práticas e concepções tradicionalistas e reacionárias, que tendem à alienação, fragmentação do conhecimento e à homogeneidade cultural. Nesse sentido, o tempo é apenas mais um fator a ser planejado e avaliado para propiciar a aprendizagem, mas nem por isso menos importante, uma vez que sua dimensão carrega intencionalidades, concepções e desdobramentos diversos, tal como elucidam os dados ora discutidos. 
Da mesma forma, a avaliação institucional poderia ser um dos mecanismos para identificação e enfrentamento dos problemas educacionais que afetam a qualidade da educação oferecida, e não um processo meramente numérico e burocrático em resposta às exigências estipuladas pelos normativas legais.

Implica considerar o tempo para além do aspecto quantitativo, com a preocupação com a qualidade do tempo escolar; subsumir a qualidade à quantidade, correndo-se o risco de dar maior ênfase sobre os processos de instrumentalização do ensino, pois "mais importante [...] do que o tempo e a quantidade de anos que o aluno passa na escola é sobretudo o que aí acontece, o que esta é capaz de significar em sua existência, os horizontes humanos e culturais que pode abrir-lhe" (COÊLHO, 2003, p. 8).

Nesse sentido, a determinação do "tempo escolar" implica definir que tipo de educação se pretende efetivar, tendo em vista o papel e os objetivos sociais mais amplos da instituição escolar. Antes de se pensar em ampliação/redução do tempo, há que se "investir num conceito de educação integral, ou seja, um conceito que supere o senso comum e leve em conta toda a integralidade do ato de educar" (PARO, 2009, p. 19), e nesta discussão, inclui-se também a discussão sobre os critérios e fundamentos para se pensar a duração dos cursos.

\section{À GUISA DE CONCLUSÃO}

Conforme destacamos em vários momentos, muito longe de responder às complexas questões que envolvem a definição da duração dos cursos de EMI nos IF, e com vistas à integração curricular e à formação integral, justamente em razão dessa complexidade, nosso objetivo principal foi verificar se há influência significativa da duração dos cursos em relação aos índices de "eficiência" acadêmica destes cursos, o que nos possibilitou contextualizar a problemática e ajudar a pensar sobre ela com base em elementos, argumentos e fundamentos mais bem organizados. É mister concluirmos que ao menos alguns indícios e fundamentos nos levam a confirmar a hipótese de que a questão da duração dos cursos de EMI nos IFs, embora não seja o fator decisivo, é de grande pertinência e influência no todo que se constitui a formação dos educandos nesse nível, etapa, forma e modalidade de ensino específicos. E, com base nisso, evidenciar com considerável sustentação estatística, teórica e contextualização institucional, que, em regra, a duração dos cursos de EMI em 4 anos e com elevada carga horária total, é um dos principais elementos que tendem a elevar os índices de evasão e retenção acadêmicas, atrasando assim, por excessos, a travessia destes estudantes para a superação da fragmentação da formação acadêmica e sua inserção no mundo do trabalho. Ou seja, em hipótese alguma trata-se de aligeirar a formação para apressar a preparação desses estudantes para o mercado de trabalho, como se fossem objetos de capitalização humana, mas também não se trata de atrasar ou impedir essa etapa de formação reiterando práticas de ensino enciclopédico ou exigindo deles muito além do adequado para a respectiva etapa da formação.

Ou seja, há sim que se considerar seriamente o lapso temporal máximo para realização dos cursos de EMI nos IFs. Do contrário, o cenário em evidência remonta mais ao antagonismo de "tempos", muito bem representados pela mitologia grega nas figuras de Chronos e Kairós. De uma perspectiva, Chronos, representando o "tempo" que 
se mede, o quantitativo absoluto, deus resoluto que devora, sem piedade, os próprios filhos. Por outro lado, Kairós, de natureza qualitativa, o deus da oportunidade, rápido, nu a ser vestido de sentidos; o presente que se apresenta e precisa ser vivido sem condições e sem tempo para se apegar ao passado ou ao futuro incerto. Ambos com suas forças e fragilidades. Chronos ou Kairós, qual é o "tempo" de formação nos cursos técnicos integrados ao Ensino Médio nos Institutos Federais de Educação, Ciência e Tecnologia?

Ao que tudo indica, não pode ser um tempo demasiado milimétrico, qual ponteiros cronológicos de um relógio mecânico alienado e instrumental, embora tenha em si todas a quantidades possíveis com tendência ao infinito. Também não pode ser de todo o tempo de Kairós, por demais incerto e rápido, com poucas chances de ser apreendido. Pelo que se sustenta, a questão não pode sequer ser apenas uma questão do divino "tempo", mas de se perceber, tal qual a teogonia grega, que um universo a se construir, entender e justificar e que, para isso, inevitavelmente se precisa de "tempo". Seja ele qual for, não pode ser qualquer um, há que se mensurar ordem no caos.

Assim, posto que ao menos a metáfora nos permite ultrapassar a barreira do tempo para auxiliar no entendimento do que é complexo, da Grécia para Roma, relembremos com o poeta Virgílio a importância de considerarmos seriamente essa discussão, afinal "Sed fugit interea fugit irreparabile tempus" (VIRGÍLIO, 1971, p. 234.) (Mas ele foge: irreversivelmente o tempo foge). Não permitamos que com ele fuja a oportunidade de pensarmos mais e melhor sobre a responsabilidade que temos em acelerar ou atrasar em demasia a formação e a travessia dos educandos que cursam a educação profissional integrada ao Ensino Médio nos IFs e que, como cada um de nós, não podem ter seus "tempos" definidos numa disputa mitológica e aleatória. Afinal, foi para romper os grilhões da submissão aos deuses que os próprios gregos nos proporcionaram o berço da razão científica.

\section{REFERÊNCIAS}

ABDIAN, Graziela Z. Revezamento teoria e prática na análise da escola pública democrática. Educar em Revista, Curitiba, Brasil, v. 34, n. 68, p. 107-122, mar./abr. 2018.

ANDRADE, Maria Margarida de. Como preparar trabalhos para cursos de Pós-Graduação: noções práticas. 5. ed. São Paulo: Atlas, 2002.

AQUINO, J. M. de; KASSOUF, A. L. Ampliação da jornada escolar melhora o desempenho acadêmico dos estudantes? São Paulo, out. 2011. Disponível em: http://anpec.org.br/encontro/2011/inscricao/arquivos/ 000-1327c2b4283497c851976b4bf6125170.pdf. Acesso em: 19 mar. 2020.

BRASIL. Lei no 11.892, de 29 de dezembro de 2008a. Institui a Rede Federal de Educação Profissional, Científica e Tecnológica, cria os Institutos Federais de Educação, Ciência e Tecnologia. D.O.U. Seção 1, de 30 de dezembro de 2008. Brasília, DF, 2008.

BRASIL. Lei no 9.394 de 20 de dezembro de 1996. Estabelece as Diretrizes e Bases da educação nacional. Disponível em: https://www.planalto.gov.br/ccivil_03/Leis/L9394.htm. Acesso em: 10 abr. 2018.

BRASIL. Constituição Federal de 1988. Promulgada em 5 de outubro de 1988. Disponível em: http://www. planalto.gov.br/ccivil_03/constituicao/constituição.htm

BRASIL. Decreto no 5.154 de 23 de julho de 2004. Regulamenta o §2의 do art. 36 e os arts. 39 a 41 da Lei nํ 9.394, de 20 de dezembro de 1996, que estabelece as diretrizes e bases da educação nacional, e dá outras providências.

BRASIL. Lei no 11.741, DE 16 de julho de 2008b. Altera dispositivos da Lei $\mathrm{n}^{\circ} 9.394$, de 20 de dezembro de 1996. Disponível em http://www.planalto.gov.br/ccivil_03/_Ato2007-2010/2008/Lei/L11741.htm\#art2 Acesso em 18 de março de 2020. 
BRASIL. Parecer CNE/CEB no 11/2012. Diretrizes Curriculares Nacionais para a Educação Profissional Técnica de Nível Médio. Parecer homologado. Despacho do Ministro, publicado no D.O.U. de 4/9/2012, Seção 1, p. 98. 68p.

BRASIL. Resolução no 6, de 20 de setembro de 2012. Define Diretrizes Curriculares Nacionais para a Educação Profissional Técnica de Nível Médio. Disponível em: http://portal.mec.gov.br/index.php?option=com_docman\&view=download\&alias=11663-rceb006-12-pdf\&category_slug=setembro-2012-pdf\&Ite$\mathrm{mid}=30192$. Acesso em: 18 mar. 2020.

BRASIL/MEC. Catálogo Nacional de Cursos Técnicos. 2017. Disponível em: http://portal.mec.gov.br/docman/novembro-2017-pdf/77451-cnct-3a-edicao-pdf-1/file Acesso em: 5 mar. 2020.

CAVALIERE, A. M. Quantidade e racionalidade do tempo de escola: debates no Brasil e no mundo. Teias, Rio de Janeiro, v. 6, n. 2, 2002.

COÊLHO, I. A educação, a cultura e a invenção de uma outra escola. ENCONTRO DE PESQUISA EM EDUCAÇÃO DA REGIÃO CENTRO-OESTE (EPECO), 6., 2003, Campo Grande. Anais [...]. Campo Grande: UCDB, 2003. CD-ROM. 10 p.

CONIF/FDE. Diretrizes indutoras para a oferta de cursos técnicos integrados ao ensino médio na Rede federal de educação profissional, científica e tecnológica. Brasília, 2018. Disponível em: http://portal.conif. org.br/images/Diretrizes_EMI_-_Reditec2018.pdf. Acesso em: 15 nov. 2018.

COSTA, Pedro Luiz de Araujo; MARINHO, Ricardo José de Azevedo. Educação profissional e tecnológica brasileira reinstitucionalizada: uma visão geral dos embates sobre a aprovação dos IFs. In: FRIGOTTO, Gaudêncio (org.). Institutos Federais de Educação, Ciência e Tecnologia: relação com o ensino médio integrado e o projeto societário de desenvolvimento. Rio de Janeiro: UERJ, LPP, 2018.

DALBOSCO, Cláudio. Pesquisa educacional e experiência humana na perspectiva hermenêutica. Cadernos de Pesquisa, v. 44, n. 154, p. 1.028-1.051, out./dez. 2014.

EIDE, E.; SHOWALTER, M. H. The effect of school quality on student performance: a quantile regression. Economics Letters, London, v. 58, p. 345-350, 1998.

FRANCO, A. M. P. Os determinantes da qualidade de educação no Brasil. 2008. 154 p. Tese (Doutorado em Economia) - Faculdade de Economia, Administração e Contabilidade, Universidade de São Paulo, São Paulo, 2008.

FREIRE, Paulo. Pedagogia do oprimido. 42. ed. Rio de Janeiro: Paz e Terra, 2005.

FRIGOTTO, Gaudêncio et al. O "estado da arte" das pesquisas sobre os IFs no Brasil: a produção discente da Pós-Graduação - de 2008 a 2014. In: FRIGOTTO, Gaudêncio (org.). Institutos Federais de Educação, Ciência e Tecnologia: relação com o Ensino Médio integrado e o projeto societário de desenvolvimento. Rio de Janeiro: UERJ; LPP, 2018. p. 83-148.

FRIGOTTO, Gaudêncio; ARAUJO, Ronaldo Marcos de Lima. Práticas pedagógicas e ensino integrado. In: FRIGOTTO, Gaudêncio (org.). Institutos Federais de Educação, Ciência e Tecnologia: relação com o ensino médio integrado e o projeto societário de desenvolvimento. Rio de Janeiro: UERJ, LPP, 2018. p. 249-266.

FRIGOTTO, G.; CIAVATTA, M.; RAMOS, M. A política de educação profissional no governo Lula: um percurso histórico controvertido. Educação \& Sociedade, Campinas, v. 26, n. 92, p. 1.087-1.113, out. 2005.

FRIGOTTO, Gaudêncio (org.). Institutos Federais de Educação, Ciência e Tecnologia: relação com o Ensino Médio Integrado e o projeto societário de desenvolvimento. Rio de Janeiro: Uerj; LPP, 2018.

IBGE. Instituto Brasileiro de Geografia e Estatística. Síntese de indicadores sociais: uma análise das condições de vida da população brasileira: 2019. Coordenação de População e Indicadores Sociais. Rio de Janeiro: IBGE, 2019.

LEE, J. W.; BARRO, R. J. Schooling Quality in a Cross-Section of Countries. Economica, London, v. 68, p. 465-488, 2001.

MINAYO, M. C. S. O desafio do conhecimento: pesquisa qualitativa em saúde. 10. ed. São Paulo: Hucitec, 2007.

PARO, V. Educação integral em tempo integral: uma concepção de educação para a modernidade. In: COELHO, Lígia Martha Coimbra da Costa (org.). Educação integral em tempo integral: estudos e experiências em processo. Petrópolis, RJ: DP et al.; Rio de Janeiro: Faperj, 2009. p. 13-20.

PISHKE, J. S. The impact of length of the school year on student performance and earnings: evidence from the German short school years. The Economic Journal, London, v. 117, p. 1.216-1.242, 2007.

PLATAFORMA NILO PEÇANHA. Disponível em: https://www.plataformanilopecanha.org. Acesso em: 31 mar. 2019. 


\section{\&Educaçăo}

Chronos ou Kairós? Qual é o "Tempo" de Formação nos Cursos Técnicos Integrados ao Ensino Médio nos Institutos Federais de Educação Ciência e Tecnologia - IFs?

RESOLUÇÃO CNE/CEB 06/2012. Define Diretrizes Curriculares Nacionais para a Educação Profissional Técnica de Nível Médio. 2012.

SOBRINHO, Sidinei Cruz. Diretrizes institucionais e a perspectiva da integração curricular no IF FarroupiIha. In: ARAÚJO, Adilson César; SILVA, Cláudio Nei Nascimento da (org.). Ensino Médio integrado no Brasil: fundamentos, práticas e desafios. Brasília: Ed. IFB, 2017. p. 106-140.

TCU. É excessiva a evasão dos cursos superiores ofertados pelos Institutos Federais de Educação Profissional e Tecnológica? In: Revista do Tribunal de Contas da União, ano 44, n. 124, maio/ago. 2012. p. 72-81. Brasília: TCU, 2012.

VIRGÍlIO, M. Georgica. In: Opere. A cura di Carlo Carena. Torino: Unione Tipografico Editrice Torinese, 1971.

WOESSMAN, L. Schooling resources, educational institutions and student performance: the international evidence. Oxford Bulletin of Economics and Statistics, Oxford, v. 65, n. 2, p. 117-170, 2003. 